\title{
The importance of atmospheric particle monitoring in the protection of cultural heritage
}

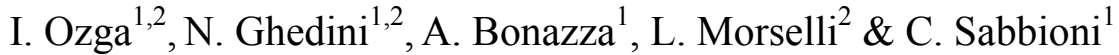 \\ ${ }^{1}$ Institute of Atmospheric Sciences and Climate, CNR, Bologna, Italy \\ ${ }^{2}$ University of Bologna, Italy
}

\begin{abstract}
It is now well known that air pollution is responsible for the accelerated damage encountered on cultural heritage located outdoors. Although several works on atmospheric pollutants have been performed, studies of atmospheric pollutant monitoring close to monuments remain rare. In addition, the few cases reported in the literature mostly regard indoor environments. As the protection and conservation of monuments and historic buildings constitutes a priority for each country, knowledge of particle composition near monuments over time is an important issue in conservation strategies. For this reason, the atmosphere in proximity of the Florence Baptistery, located in the city centre, was continuously monitored during 2003 and 2004 by means of aerosol sampling performed close to two of the three doors of the monument. In particular, the monitoring was performed close to the North Door, realized by Lorenzo Ghiberti (1403-1424), currently utilized as the entrance to the monument, and the South Door, a masterpiece of Andrea Pisano (1330), employed as the exit for visitors. The sampling sites were characterized by different expositions to road traffic emissions. The non-carbonate carbon and soluble ionic components of the total suspended matter were measured. The data obtained is presented and discussed with the goal of contributing to the formulation of guidelines for a suitable safeguard of the built cultural heritage.
\end{abstract}

Keywords: monitoring, urban pollutants, non-carbonate carbon, ions, conservation, cultural heritage. 


\section{Introduction}

Since human history is documented by the artistic-cultural heritage, its preservation in time is a priority for all countries. Moreover, every year movable and immoveable heritage attracts millions of visitors, incrementing tourism and constituting an important source of income. Thus, the safeguard, conservation and maintenance of cultural heritage constitute a common challenge of all nations, and the least onerous strategy, but the one most able to protect the artworks, is to avoid damage by reducing the potential causes. Today, anthropogenic air pollution represents an element of serious risk to the preservation of works of art, particularly cultural heritage located outdoors [1]. Such historic monuments and buildings are the most susceptible to deterioration risks because as they are mainly located in city centres, directly exposed to atmospheric pollutants, which are the main cause of damage in urban areas [2].

The conservation of monumental heritage is directly correlated with the atmospheric pollution and its future depends on the reduction of air pollutants. Thus the monitoring pollution and surface deposition must be among the main goals in cultural heritage preservation [3]. In urban areas, outdoor stone and metal artworks are particularly vulnerable to pollutant action $[4,5]$, particularly to gases and particles from combustion processes, the main cause of the aesthetic and material damage encountered today on the monumental and built heritage $[6,7]$.

To protect cultural heritage effectively it is necessary to have a detailed knowledge of the characteristics of the environment in which single assets are situated. Such information is a fundamental pre-requisite for identifying and quantifying multi-pollutants, singling out emission sources, calculating the entity of deposition on the various materials of interest, forecasting and estimating the damage potential, setting tolerance thresholds, and establishing mitigation and adaptation strategies.

In the past, the attention of researchers was focused mainly on gaseous pollutants, especially sulphur dioxide, considered to be one of the most important causes of stone deterioration $[8,9]$. However, in recent years a change has come about: in many areas of Europe, levels of $\mathrm{SO}_{2}$ have been reduced, while the increase in automobile traffic has brought in its wake a rise in levels of ozone concentrations and total suspended particulate (TSP), and, among the constituents of the latter, there has been an increase in carbonaceous and nitrogenous fractions. This has generated an entirely new air pollution scenario $[10,11]$.

Ever-increasing human activities have produced a continual enrichment of the carbonate fraction in suspended particulate, which is drawing increasing attention of researchers. Carbonaceous particles are not only the cause of the black colour of the patinas that mar the appearance of monuments and buildings [12], but it has also been demonstrated that they play an active role in calcite sulphation, because of their sulphur content and the presence of heavy metals, which trigger the said process [13]. Moreover, due to their high specific surface 
$\left(10-100 \mathrm{~m}^{2} / \mathrm{g}\right)$, they themselves act as a catalytic support in deterioration reactions [14].

The preservation of cultural heritage and its protection against possible damage due to atmospheric air pollution has only recently become the focus of well-deserved scientific interest. So far, very little coherent work has been performed to assess and monitor the impact of air pollution on the most important historic buildings and monuments, with the aim of protecting them from damage. Most of the monitoring undertaken in urban areas has been with a view to studying the health-related effects of air pollution. Thus, the assessment of the impact of multi-pollutants is based on monitoring that is generally performed according to the air quality directives adopted for the protection of human health. The resulting data often regards samples collected far from monuments of interest, and obviously do not allow the evaluation of the spatial and temporal variations of multi-pollutants in proximity to the monuments to be protected.

In order to investigate variation trends in particle quantity and composition in the air immediately surrounding monuments of historic-artistic importance, during 2003 and 2004 atmospheric monitoring was carried out in the area of the Baptistery in Florence, and particularly close to the two famous bronze doors realized by Lorenzo Ghiberti (Northern Door) and Andrea Pisano (Southern Door).

The aim of this work is to characterize the local atmosphere around the Baptistery. The results of the study will be of use to cultural heritage managers, and especially the authorities responsible for the preservation of the Florence Baptistery.

\section{Materials and methods}

The Baptistery of Florence (fig. 1) is situated in the historic city centre, in an area mainly reserved for pedestrians, with the exception of one road bearing intense traffic of heavy diesel-run vehicles (more than 2000 buses a day ARPAT 2003), accessible also to motorcycles and taxis, which run a few meters' distance from the north-facing Door.

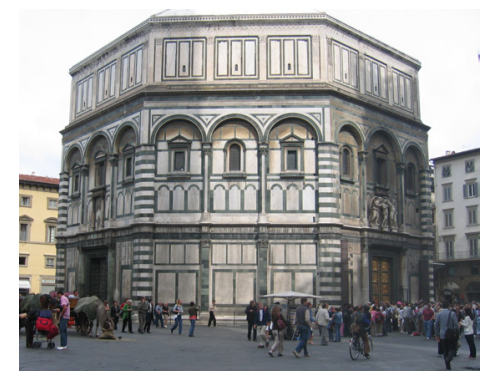

Figure 1: The Baptistery in the center of Florence. 
The specific location of the monument means that its sides have a different exposition to pollutant agents, in particular the two bronze doors of the northern and southern sides: the North Door (ND), the work of Lorenzo Ghiberti (14031424), is currently used as the entrance to the monument, and the more ancient South Door (SD), a splendid example of Gothic sculpture, masterpiece of Andrea Pisano (1330), is used as the visitor exit.

Sampling of total suspended particulate (TSP), i.e. without granulometric selection, was performed by the Agenzia Regionale per la Protezione Ambientale della Toscana (ARPAT) using two TECORA samplers, equipped with membrane filter systems $(\varnothing=47 \mathrm{~mm})$, positioned in proximity to each of the two doors. Each system consists of several sampling lines: quartz fibre filters were positioned on two of them, for the determination of organic substances and carbon, while the other two were equipped with polycarbonate membranes, used to determine the ionic fraction and for morphological analyses.

TSP sampling took place from February 2003 to November 2004 in the form of nine three-day seasonal campaigns: winter (December, January, February), spring (March, April, May), summer (June, July, August), and autumn (September, October, November).

On the TSP, measurements were performed of the soluble ionic, anionic and cationic components, as well as non-carbonate carbon (NCC), i.e. the fraction not linked to soil dust.

For the measurement of the soluble saline fraction carried out by ion chromatography (IC), a Dionex Chromatograph model 4500i with conductivity detector (Dionex CD II) was used. During the analyses the addition of fructose prevents the oxidation of the sulphites and sulphates [15]. The cations measured were: lithium, sodium, potassium, ammonium, magnesium, calcium, strontium, manganese, and the following anions: sulphate, bisulphite, nitrate, nitrite, fluoride, chloride, bromide, hydrogenophosphate, formate, acetate, oxalate.

The analysis of the carbonaceous fraction was determined by combustion/gas chromatography, using a specific analytical methodology designed, developed and validated for carbon measurements in complex, minimal mass samples, such as those consisting of aerodisperse particulate collected on a filter. For the analysis of NCC, portions of filter of known area (fig. 2) are weighed and introduced into the instrument's silver micro-crucible.

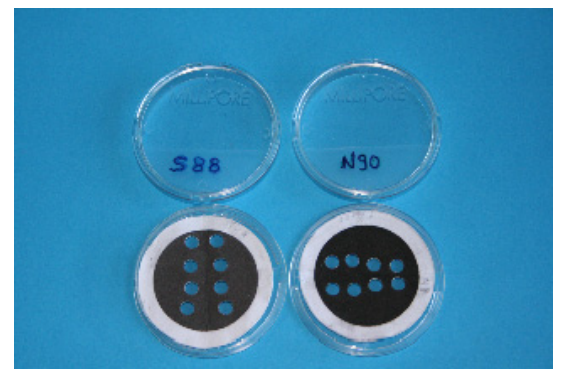

Figure 2: Quartz fibre filters without the portions used for NCC analysis (sampled from SD on the left and ND on the right). 
Subsequently, $5-10 \mu \mathrm{l}$ of $50 \% \mathrm{HF}$ solution is added in order to eliminate the quartz through the formation of soluble, highly volatile, and strongly acid $\mathrm{SiF}_{4}$. The crucible is then maintained for 24 hours in a dryer containing potassium hydroxide, in order to eliminate $\mathrm{SiF}_{4}$, excess $\mathrm{HF}$ and water. The dry residue remaining in the crucible is analysed employing a CHNSO EA 1108 FISONS Instrument. The same pre-treatment and the same measurement are performed also on a blank filter and the measured quantity of non-carbonate carbon (NCC) is subtracted from those obtained on particulate samples deposited on the filter.

\section{Results and discussion}

IC data of all samples collected near both northern door (ND) and southern door (SD) during the two year period indicates that the major anions are $\mathrm{SO}_{4}{ }^{-}, \mathrm{NO}_{3}{ }^{-}$ and $\mathrm{Cl}^{-}$and the major cations are $\mathrm{Ca}^{++}, \mathrm{Na}^{+}$and $\mathrm{Mg}^{++}$.

In figures 3 and 4 the concentrations of the anions sulphate and nitrate show, at the two sampling sites, rather similar trends during 2003 and 2004, but with mean seasonal concentrations higher at $\mathrm{ND}$ than $\mathrm{SD}$. In general, while $\mathrm{SO}_{4}{ }^{2}$ concentrations undergo an appreciable decrease during the two years period those of $\mathrm{NO}_{3}{ }^{-}$are on the rise. This increase in mean concentrations of $\mathrm{NO}_{3}{ }^{-}$, from 2003 to 2004 is particularly evident in winter and spring, when fuel consumption increases due to the greater demand for heating. In all seasons, both in 2003 and 2004, the quantities of $\mathrm{NO}_{3}{ }^{-}$measured at ND are higher than those recorded at $\mathrm{SD}$.

These results reflect the gradual reduction of the sulphur content in fuels and, at the same time, their increased consumption.

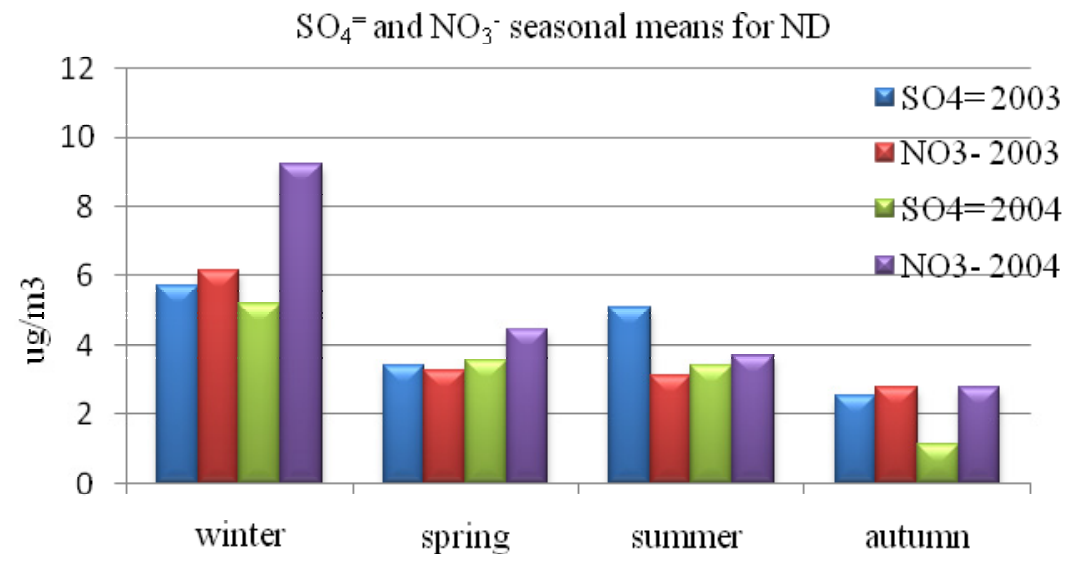

Figure 3: Seasonal means of sulphate and nitrate anions at ND in the monitoring period. 
Chlorides are always present in considerable concentrations in all the aerosol samples analysed. In winter, spring and autumn at ND, mean total values of $\mathrm{Cl}^{-}$ are much higher than those measured at $\mathrm{SD}$, while in summer the mean concentration measured at SD are about double the one detected at ND $(0.50 \mathrm{e}$ $0,99 \mu \mathrm{g} / \mathrm{m}^{3}$, respectively).

In the two-year period in question, measurements of organic anions show acetates to have the highest mean concentrations at both sampling sites $\left(0.81 \mu \mathrm{g} / \mathrm{m}^{3}\right.$ at $\mathrm{ND}$ and $0.87 \mu \mathrm{g} / \mathrm{m}^{3}$ at $\left.\mathrm{SD}\right)$, followed by oxalates and formates. With regard to organic anions, no major differences between the concentrations measured at ND and SD are observed throughout the period under consideration.

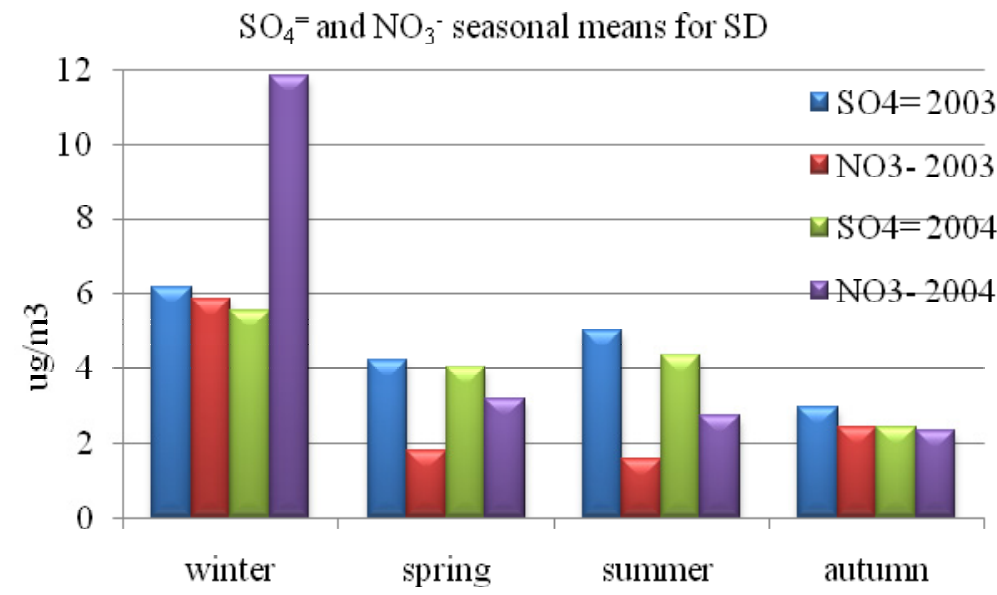

Figure 4: Seasonal means of sulphate and nitrate anions at SD in the monitoring period.

Since organic anions have a number of natural and anthropogenic origins [16], their yearly mean concentrations do not reveal particular variations. However, at ND the highest concentration is observed for $\mathrm{C}_{2} \mathrm{H}_{3} \mathrm{O}_{2}{ }^{-}$in winter and for $\mathrm{C}_{2} \mathrm{O}_{4}{ }^{=}$and $\mathrm{CHO}_{2}{ }^{-}$in spring, while at $\mathrm{SD}$ the highest concentrations are measured for $\mathrm{C}_{2} \mathrm{H}_{3} \mathrm{O}_{2}^{-}$and $\mathrm{C}_{2} \mathrm{O}_{4}{ }^{-}$in winter and $\mathrm{CHO}_{2}{ }^{-}$in autumn.

The cations monitored at the two doors are found to have very similar seasonal mean concentrations during both years (fig. 5, 6).

In 2003 and $2004, \mathrm{Ca}^{++}$and $\mathrm{Mg}^{++}$ions are the cations that are always present in the highest concentrations in the sampled aerosol, both at ND and SD. The origin is natural, being among the dominant macro-constituents of the earth's crust. The $\mathrm{Ca}^{++}$presents the same seasonal trend at ND and SD, reaching a maximum concentration in spring (5.20 and $7.04 \mu \mathrm{g} / \mathrm{m}^{3}$, respectively) and a minimum in autumn $\left(2.57\right.$ and $\left.2.04 \mu \mathrm{g} / \mathrm{m}^{3}\right)$. With regard to $\mathrm{Mg}^{++}$, the maximum is reached in spring at ND $\left(0.89 \mu \mathrm{g} / \mathrm{m}^{3}\right)$ and in winter at SD $\left(0.48 \mu \mathrm{g} / \mathrm{m}^{3}\right)$, while the minimum occurs in summer at both doors. On average over the two-year period, at both ND and $\mathrm{SD}, \mathrm{Na}^{+}$shows maximum concentrations in winter and autumn, and minimum in spring and summer. The $\mathrm{K}^{+}$ion is present in higher 
quantities in winter and summer at ND and SD, while lower ones are encountered in autumn and spring at both doors. In winter and summer, the $\mathrm{NH}_{4}{ }^{+}$ ion has higher mean seasonal concentrations at both ND and SD, while the minimum is found at ND in spring and at SD in autumn.

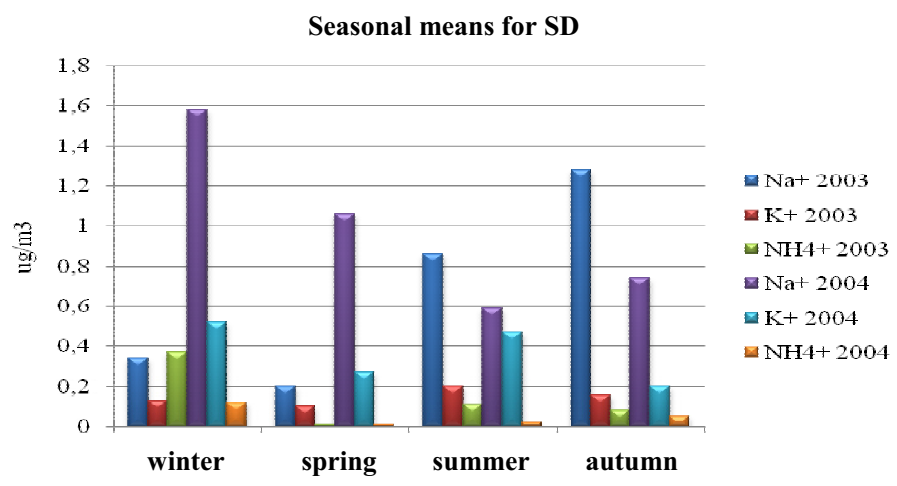

Figure 5: $\quad$ Seasonal mean concentrations of $\mathrm{Na}^{+}, \mathrm{K}^{+}$and $\mathrm{NH}_{4}^{+}$ions at ND in the monitoring period.

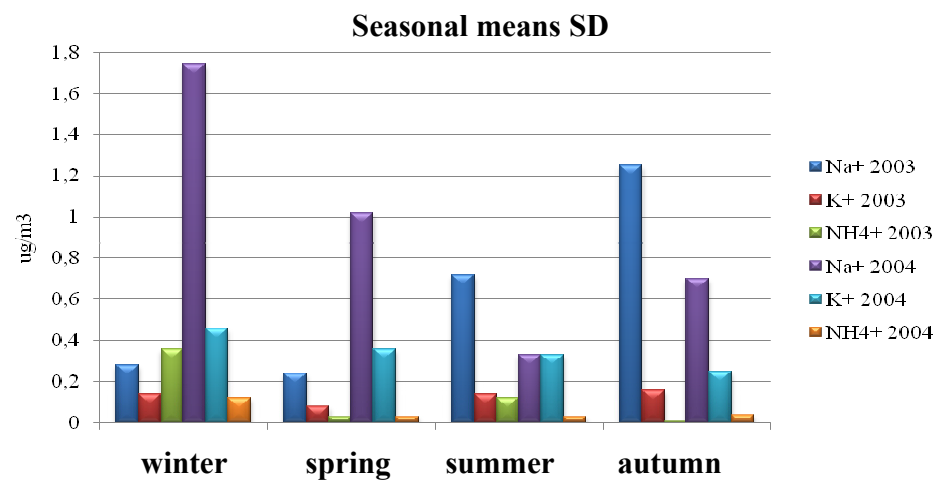

Figure 6: Seasonal mean concentration for $\mathrm{Na}^{+}, \mathrm{K}^{+}$and $\mathrm{NH}_{4}^{+}$ions at $\mathrm{SD}$ in the monitoring period.

Regarding NCC, the concentrations measured at ND are always higher than those measured at SD in the same period (fig. 7, 8).

In fact the overall mean of NCC shows higher values at ND compared to SD (18.55 and $14.84 \mu \mathrm{g} / \mathrm{m}^{3}$, respectively) and, at both doors, the annual mean of NCC is higher in 2004 than in 2003. On a seasonal basis, again in terms of mean values of NCC relative to the period February 2003-October 2004, at ND and $\mathrm{SD}$, respectively, the quantities measured are: 20.15 and $15.40 \mu \mathrm{g} / \mathrm{m}^{3}$ in winter, 18.12 and $17.90 \mu \mathrm{g} / \mathrm{m}^{3}$ in spring, 17.10 and $13.67 \mu \mathrm{g} / \mathrm{m}^{3}$ in summer, and 17.48 and $12.03 \mu \mathrm{g} / \mathrm{m}^{3}$ in autumn. 


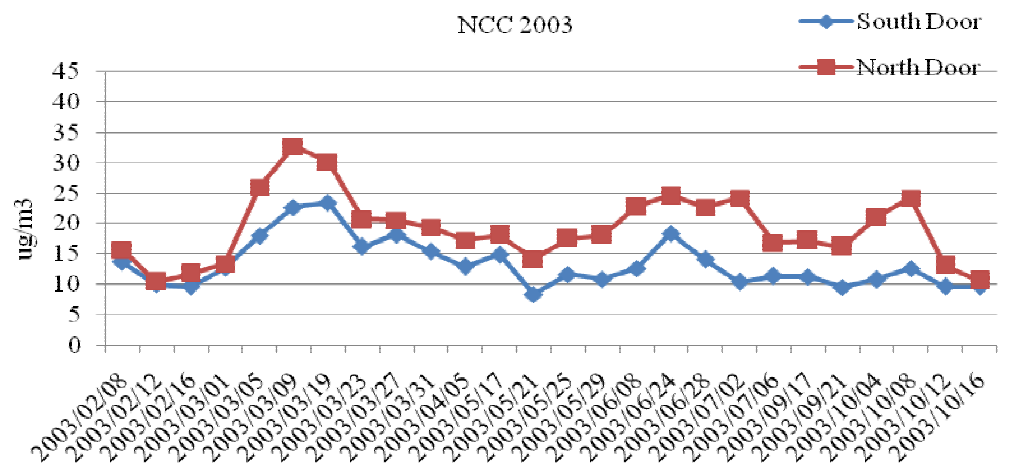

Figure 7: Non-carbonate carbon measured in 2003 at both Baptistery doors.

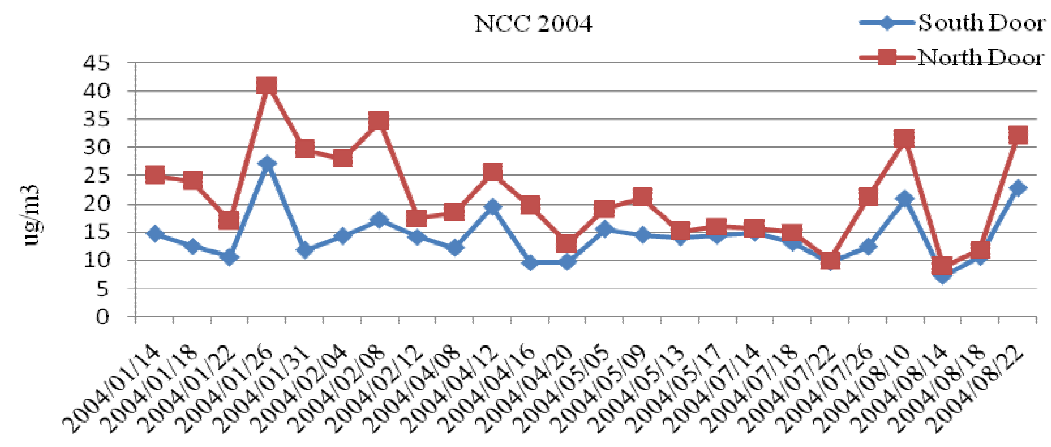

Figure 8: Non-carbonate carbon measured in 2004 at both the Baptistery doors.

The comparison among the seasonal mean values of NCC (fig. 9) shows that, in 2003, the highest concentration was in summer at ND and in spring at SD, while in 2004, the highest concentrations are those found in winter at ND and in spring at SD. In 2003 the lowest seasonal values of NCC are those relating to the winter at ND and to autumn at SD, while in 2004 the minima are recorded in summer at both ND and SD. The different seasonal trends for mean NNC concentrations during 2003 and 2004, can be explained by the high temperature and exceptional lack of precipitations recorded in the summer of 2003. During summer 2003 due to high temperatures and prolonged drought, the increase of TSP concentration was affected by road and soil dust re-suspension.

Such re-suspension was favoured by the flow of tourists and, at ND where visitors queue at length to purchase entrance tickets, there is an excellent correlation between concentrations of NCC and TSP. 


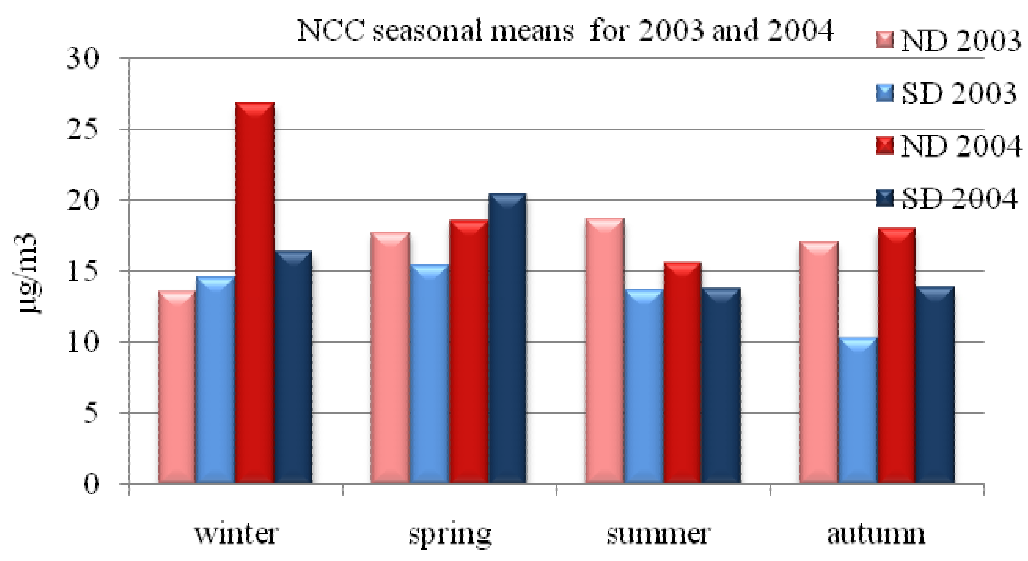

Figure 9: NCC seasonal mean concentration, for 2003 and 2004, at the two doors.

The mass balance based on the results obtained show that, at ND, the aerosol consists on average of about $27 \%$ NCC, $9 \%$ cations, $15 \%$ anions and the rest, approximately $49 \%$, constitutes the non determinate fraction (soil dust); at SD it is composed on average of about $25 \% \mathrm{NCC}, 12 \%$ cations, $18 \%$ anions and about $45 \%$ non determinate fraction.

\section{Conclusions}

Since the degradation of historic monuments and buildings situated outdoors is known to depend on their exposure to airborne chemical, physical and biological agents, continuous monitoring was performed of TSP in proximity to two of the three doors of the Florence Baptistery, the north-facing and south-facing ones. The study aimed to assess the impact of multi-pollutants by measuring their concentrations in the atmosphere close to the monument. The results obtained give evidence of pollution due to fossil fuel (diesel, petrol) combustion processes, typical of urban centres, the source being emissions by both mobile and fixed combustion sources such as vehicles, domestic heating systems and industrial activities. Because of its location, northern door (ND) turns out to be more exposed to the action of atmospheric multi-pollutants than southern door (SD), nearly always showing higher concentrations of TSP, $\mathrm{NCC}$ and $\mathrm{NO}_{3}{ }^{-}$.

While the mean concentration of $\mathrm{SO}_{4}{ }^{2}$ gradually decreases over time, that of $\mathrm{NO}_{3}{ }^{-}$undergoes an increase from 2003 to 2004, especially in winter and spring. In all seasons, concentrations of the nitrate anion at ND are higher than those measured at SD, in both 2003 and 2004, and this difference can be attributed to the emissions of the intense vehicular traffic characterizing the road adjacent to ND. 
The mean concentration of NCC also rises from 2003 to 2004, with a trend over time similar to that of TSP. The quantity of NCC measured at ND (on average about $27 \%$ of TSP) always turns out higher than that at SD (about $25 \%$ of TSP). Here again the higher values can reasonably be attributed to the emissions of the heavy traffic (cars, heavy diesel-run vehicles, taxis, motorcycles) running along the road at about three meters distance from ND, which is therefore directly exposed, while SD is only indirectly exposed. At both $\mathrm{ND}$ and $\mathrm{SD}$ the ions $\mathrm{NH}_{4}^{+}$and $\mathrm{SO}_{4}{ }^{*}$ show the same mean seasonal trend, which seems to point to a common origin.

Most aerosol samples showed significant concentrations of acetates and oxalates, near both ND and SD. The origin, particularly that of the oxalate ion, remains an unresolved problem, since neither an anthropogenic nor biological origin can be excluded with certainty. In this case too, it is likely that both combine to determine the quantities measured during the two years monitored. The constant absence of sulphites underscores the oxidant character of the local atmosphere.

The results obtained show how the concentration and composition of particles, especially those relative to ND, appears to be influenced by the presence of visitors in the area of the Baptistery, emphasizing that tourism can have a strong impact on the re-suspension of particulate (road-soil dust), especially in the dry period. The monitoring carried out ascertains that every monument located outdoors is exposed to chemical, physical and biological agents characterizing the area in which it is situated. Thus, only extensive local monitoring can produce the data required to identify and quantify them. The study also shows that, even in outdoor environments, the flow of visitors in proximity to cultural heritage (fruition) can influence the surrounding atmospheric aerosol.

Because of the crucial role of atmospheric pollutants in the damage of cultural heritage, especially in urban areas, atmospheric pollutant monitoring close to single monuments and historic buildings is necessary to establish correct mitigation and adaptation strategies, specific for each site of interest, to protect it from degradation and preserve it for future generations.

\section{Acknowledgements}

The authors wish to thank the Agenzia Regionale per la Protezione Ambientale della Toscana (ARPAT) for performing the atmospheric particles sampling within the "Progetto Battistero: studio dell'impatto ambientale sui monumenti nel centro urbano di Firenze".

This work was performed within the "European Ph.D. in Science for Conservation (EPISCON)" funded by the European Commission with 6FP EUMarie Curie EST Action and within the EC Project "Technologies and Tools to prioritize Assessment and diagnosis of air pollution impact on immovable and movable Cultural Heritage (TeACH)"'(contract number: 212458). 


\section{References}

[1] Rossval, J., Air Pollution and Conservation, Elsevier, Amsterdam, 1988.

[2] Brimblecombe, P., The effects of air pollution on the built environment, Air Pollution Reviews, Vol. 2, Imperial College Press, London, 2003.

[3] Morselli, L., Bernardi, E., Passarini, F., The City of Tomorrow: Towards a Definition of "Limit Values" for the Pollutants in Relation to Decay of Cultural Heritage. A Proposal. Environmental Science and Pollution Research - International, 9, pp. 287-288, 2002.

[4] Bernardi, E., Chiavari, C., Lenza, B., Martini, C., Morselli, L., Ospitali, F., Robbiola, L., The atmospheric corrosion of quaternary bronzes: the leaching action of acid rain. Corrosion Science, 51, pp. 159-170, 2009

[5] Camaiti, M., Bugani, S., Bernardi, E., Morselli, L., Matteini, M., Effects of atmospheric $\mathrm{NO}_{\mathrm{x}}$ on biocalcarenite coated with different conservation products. Applied Geochemistry, 22, pp. 1248-1254, 2007.

[6] Sabbioni, C., \& Zappia, G., Decay of sandstone in urban areas correlated with atmospheric aerosol. Water, Air and Soil Pollution, 63, pp. 305-316, 1992.

[7] Sabbioni, C., Zappia, G., Gobbi, G., Carbonaceous particles and stone damage in a laboratory exposure system. Journal of Geophysical Research, 101, pp. 19621-19627, 1996.

[8] Sabbioni, C., Contribution of atmospheric deposition to the formation of damage layers. Science of the Total Environment, 167, pp. 49-56, 1995.

[9] Gobbi, G., Zappia, G., Sabbioni, C., Anion determination in damage layers of stone monuments. Atmospheric Environment, 29A, pp. 703-707, 1995.

[10] Jacob, D.J., Introduction to atmospheric chemistry, Princeton University Press, Princeton, pp. 144-159, 2000.

[11] Bonazza, A., Sabbioni, C., \& Ghedini, N., Quantitative data on carbon fractions in interpreting black crusts and soiling on European built heritage. Atmospheric Environment, 39, pp. 2607-2618, 2005.

[12] Grossi, C. M., Esbert, R. M., Diaz-Pache, F., Alonso F. J., Soiling of building stones in urban environments. Building and Environment, 38, pp. 147-159, 2003.

[13] Rodríguez-Navarro, C., \& Sebastián, E., Role of particulate matter from vehicle exhausts on porous building stone (limestone) sulphation. The Science of the Total Environment, 187, pp. 79-91, 1996.

[14] Benner, W.H., Brodzinsky, R., Novakov, T., Oxidation of $\mathrm{SO}_{2}$ in droplets which contain soot particles. Atmospheric Environment, 16, pp. 13331339, 1982.

[15] Gobbi, G., Zappia, G., Sabbioni, C., Sulphite quantification on damaged stones and mortars. Atmospheric Environment, 32, pp. 783-789, 1998.

[16] Sabbioni, C., Ghedini, N., \& Bonazza, A., Organic anions in damage layers on monuments and buildings. Atmospheric Environment, 37, pp. 1261-1269, 2003. 